\title{
Dexamethasone Suppression Test Status and Severity of Depression
}

\author{
James H. Meador-Woodruff, John F. Greden, Leon Grunhaus, and \\ Roger F. Haskett
}

\section{Introduction}

Many patients with major depressive disorder (MDD) develop state-dependent hypothalamicpituitary-adrenal (HPA) axis dysregulation (Carroll et al. 1981). A complex interaction of factors contributes to this abnormality. Severity of illness (Kumar et al. 1986; Meador-Woodruff et al. 1987; Miller and Nelson 1987), age (Oxenkrug et al. 1983; Davis et al. 1984; Lewis et al. 1984), and degree of recent weight loss (Keitner et al. 1985; Krishnan et al. 1985b) are seemingly three of the most important determinants.

Severity of depression has been shown to correlate moderately with and to contribute significantly to the total variance of postdexamethasone cortisol levels in patients with MDD, at both the pituitary and adrenal levels of the HPA axis. Many reports, however, have found this correlation by studying subjects who were operationally defined as either Dexamethasone Suppression Test (DST) nonsuppressors or suppressors. DST nonsuppressors have high postdexamethasone cortisol levels by definition and

From the Clinical Studies Unit of the University of Michigan Depression Program, Department of Psychiatry, University of Michigan Medical Center, Ann Arbor, MI.

Supported in part by NIMH Grant RO1-40216 (I.F.G.) and the Department of Psychiatry and the Theophile Raphael Fund at the University of Michigan Medical Center.

Address reprint requests to $\mathrm{Dr}$. James H. Meador-Woodruff, Department of Psychiatry, Mental Health Research Institute, University of Michigan Medical Center, 205 Washtenaw Place, Ann Arbor, MI 48109.

Received December 21, 1987; revised February 29, 1988. tend to be more severely depressed than DST suppressors (Reus 1982; Sangal et al. 1984; Krishnan et al. 1985a). Accordingly, the correlation between severity of illness and postdexamethasone cortisol levels may be an artifact secondary to defining DST suppressor status. To examine this possibility, we studied the relationship between severity of depression and postdexamethasone cortisol levels in a group of patients with MDD, but with the strategy of evaluating DST suppressors and nonsuppressors separately.

\section{Methods}

Subjects consisted of 114 patients treated in the University of Michigan Depression Program and Clinical Studies Unit of the Department of Psychiatry. All patients underwent a comprehensive diagnostic evaluation, including several clinical interviews by psychiatrists, a structured interview by a trained research staff member using the Schedule for Affective Disorders and Schizophrenia (Spitzer and Endicott 1975), a detailed family history and social assessment by a social worker, and a thorough physical and laboratory evaluation. Diagnosis was made by consensual agreement of the clinicians involved in gathering the above information using Research Diagnostic Criteria (RDC) (Spitzer et al. 1977).

Patients included in the present study (1) met RDC for MDD, (2) did not meet psychotic subtype, (3) completed a DST following a medi- 
cationmfree period of at least 2 weeks, (4) had a 17-item Hamilton Rating Scale for Depression (HSRD) (Hamilton 1960) administered at the time of the DST, (5) had no identifiable technical exclusions known to invalidate the DST (Carroll et al. 1981), and (6) gave written informed consent to participate in these research activities.

Samples were obtained for postdexamethasone plasma cortisol determination at 8:00 $\mathrm{AM}$, 4:00 PM, and 11:00 PM, although fewer than all three samples were obtained from most patients (8:00 AM, $\mathrm{n}=20 ; 4: 00 \mathrm{PM}, \mathrm{n}=112,11: 00$ $\mathrm{PM}, \mathrm{n}=51$ ). We determined plasma cortisol concentration using a modification of Murphy's (1967) competitive protein-binding technique. Maximum postdexamethasone plasma cortisol levels were logarithmically transformed to improve normality prior to correlational analyses. We defined DST nonsuppression as a maximum postdexamethasone plasma cortisol level $\geqslant 5$ $\mu \mathrm{g} / \mathrm{dl}$. Comparisons between DST suppressors and nonsuppressors were by two-tailed $t$-tests or the $\mathrm{X}^{2}$ test, as appropriate.

\section{Results}

A highly significant correlation was found between HRSD scores and maximum postdexamethasone plasma cortisol levels for the entire patient population, as shown in Figure 1, generating the regression equation $y=-2.48+$ $0.36 x(\mathrm{n}=114$, $\mathrm{df}=112, r=0.40, p<$ $0.0001)$. When divided into DST suppressors and nonsuppressors, the same general relationship persisted: the nonsuppressors manifested a significant relationship between HRSD scores and maximum postdexamethasone plasma cortisol levels $(\mathrm{y}=1.93+0.41 x ; \mathrm{n}=34$, df $=32, r=0.44, p<0.01$ ), as did the DST suppressors $(y=0.99+0.041 x ; \mathrm{n}=80, \mathrm{df}$ $=78, r=0.22, p<0.05)$.

Given earlier reports suggesting that age and degree of recent weight loss are also important determinants of the HPA axis dysregulation seen in depression, the influence of these variables on the observed severity-cortisol relationship was determined. HRSD scores, age, and degree of recent weight loss were entered into a multiple linear regression analysis with postdexamethasone plasma cortisol as the dependent variable. For the entire study group, a significant relationship was found (multiple $r=0.48, p$ $<0.0001)$. Partial correlation coefficients were: HRSD score, $r=0.29$ ( $p<0.002)$; age, $r=$ $0.30(p<0.002)$; and weight loss, $r=0.07$. When only the nonsuppressors were studied, a similar correlation was found (multiple $r=0.47$, $p=0.06$ ). In this case, partial correlation coefficients were: HRSD score, $r=0.42(p<0.02)$; age, $r=0.13$; and weight loss, $r=0.17$. Finally, when the DST suppressors were studied, a significant relationship was found (multiple $r=0.35, p<0.02$ ), with partial correlation coefficients of $0.18(p=0.12), 0.24$ ( $p$ $<0.05$ ), and 0.11 for HRSD score, age, and weight loss, respectively. Age and severity, but not weight loss, appear to be factors contributing to the HPA axis dysregulation observed in this particular group of patients. When the effects of age and weight loss are accounted for, significant relationships between HRSD score and postdexamethasone plasma cortisol persist for the entire group and for the DST nonsuppressors; the relationship between these two variables exhibits a trend toward significance for the DST suppressors.

To explore possible differences between the DST suppressors and nonsuppressors, various clinical and demographic variables were compared, as indicated in Table 1. The DST nonsuppressors were significantly older and more severely depressed than the suppressors, whereas other factors were not appreciably different.

\section{Discussion}

A growing number of studies concur that severity of depression is a significant determinant of the HPA axis dysregulation associated with MDD (Kumar et al. 1986; Meador-Woodruff et al. 1987; Miller and Nelson 1987). Our results indicate that this relationship is not simply an artifact related to the definition of DST suppressors and nonsuppressors. Rather, both DST suppressors and nonsuppressors exhibit a sig- 


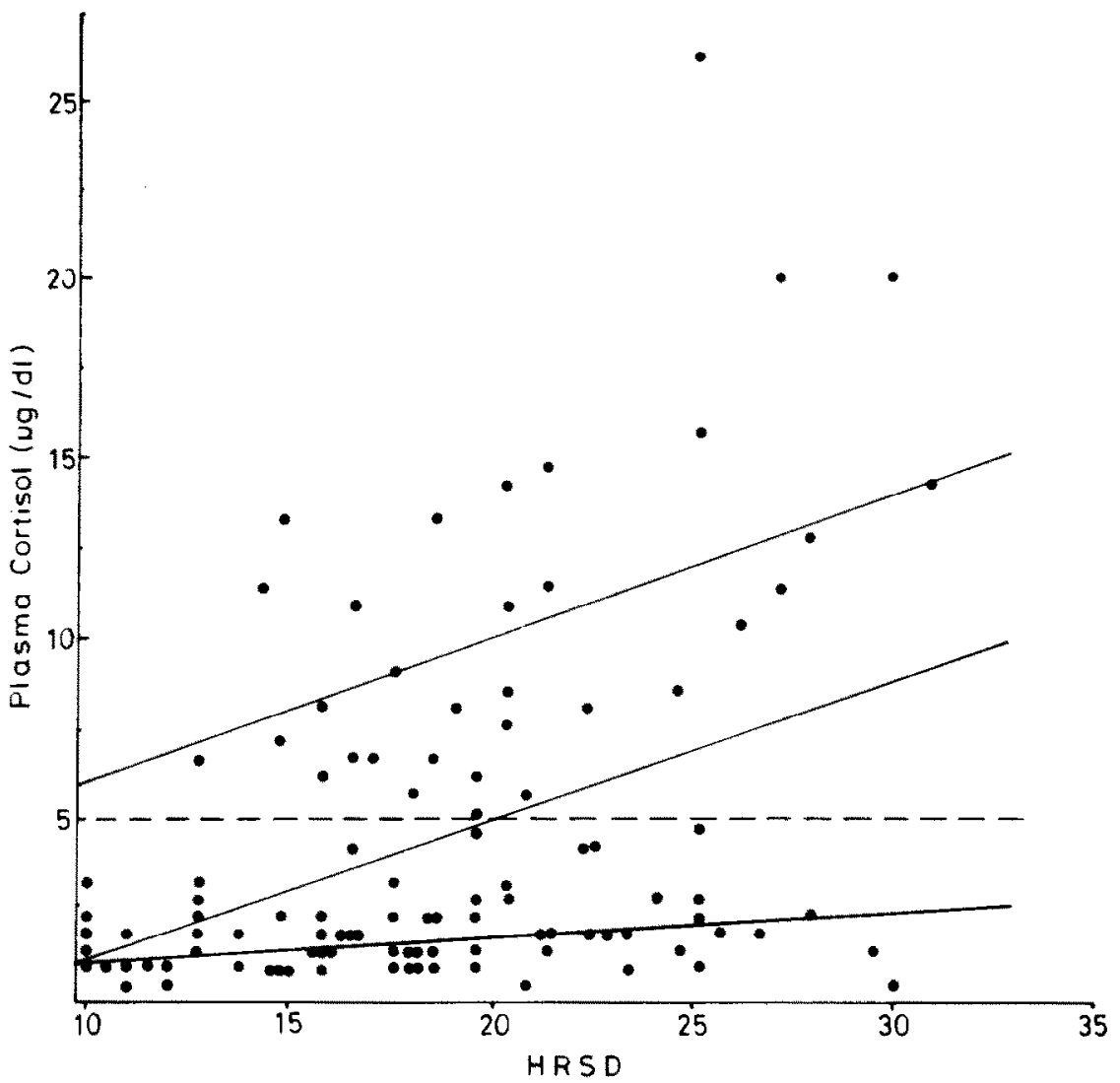

Figure 1. Scattergram of HRSD scores and maximum postdexamethasone plasma cortisol levels. Dashed line indicates division between DST suppressors and nonsuppressors. Center regression line is for the entire population; upper and lower lines represent DST nonsuppressors and suppressors, respectively. All three regression lines are statistically significant.

Table 1. Clinical and Demographic Variables of DST Suppressors and Nonsuppressors

\begin{tabular}{lcccc}
\hline Variable & Suppressors & Nonsuppressors & Statistic & $p$ \\
\hline $\mathrm{n}$ & 80 & 34 & & \\
Age (years) & $37.3 \pm 14.2^{a}$ & $47.0 \pm 16.2$ & $t=3.18$ & $<0.002$ \\
HRSD & $17.9 \pm 5.3$ & $21.6 \pm 5.4$ & $t=3.32$ & $<0.005$ \\
Weight change $(\mathrm{kg})$ & $+0.60 \pm 8.9$ & $-2.59 \pm 8.1$ & $t=-1.74$ & $\mathrm{NS}$ \\
$\begin{array}{l}\text { Past depressive cpisodes } \\
\text { Inpatients/ } \\
\quad \text { outpatients }\end{array}$ & $2.4 \pm 3.1$ & $2.4 \pm 2.9$ & $t=0.01$ & $\mathrm{NS}$ \\
$\begin{array}{l}\text { Female/male } \\
\text { Unipolar/ } \\
\quad \text { bipolar }\end{array}$ & $37 / 43$ & $20 / 14$ & $\mathrm{X}^{2}=1.51$ & $\mathrm{NS}$ \\
$\begin{array}{l}\text { Postdexamethasone } \\
\text { plasma cortisol }(\mu \mathrm{g} / \mathrm{d})\end{array}$ & $49 / 31$ & $21 / 13$ & $\mathrm{X}^{2}=0.00$ & $\mathrm{NS}$ \\
\hline
\end{tabular}

Mean \pm standard deviation. 
nificant relationship between maximum postdexamethasone plasma cortisol levels and HRSD scores, just as the total combined population does. Although differences in degree of severity of depression exist between the DST suppressors and nonsuppressors, both manifest a correlational relationship between severity of depression and plasma cortisol, even when the effects of age and degree of recent weight loss are accounted for.

These results also suggest that the use of a cutpoint of postdexamethasone plasma cortisol levels should be used in conjunction with other measures when studying the neuroendocrinology of depression. Originally, the DST was standardized in an attempt to find a laboratory correlate specific to endogenous depression (Carroll et al. 1981). Although referent values may be essential for determining sensitivity and specificity, our results indicate that they should not be overemphasized or used in isolation, especially in studies attempting to explore the physiology of this system. A relationship exists between maximum postdexamethasone plasma cortisol levels and severity of depression, regardless of DST suppressor status, and should be considered in any study involving HPA axis endocrinology in affective disorders.

\section{References}

Carroll BJ, Feinberg M, Greden JF, Tarika J, Albala AH, Haskett RF, James NMcl, Kronfol Z, Lohr N, Steiner M, de Vigne JP, Young EA (1981): A specific laboratory test for the diagnosis of melancholia. Standardization, validation, and clinical utility. Arch Gen Psychiatry 38:1522.

Davis KL, Davis BM, Mathe AA, Mohs RC, Rothpearl $A B$, Levy MI, Gorman LK, Berger P (1984): Age and the Dexamethasone Suppression Test in depression. Am I Psychiatry 141:872-874.
Hamilton M (1960): A rating scale for depression. J. Neurol Neurosurg Psychiatry 23.56-62.

Keitner GI, Brown WA, Qualls CB, Haier RJ, Barnes KT (1985): Results of the Dexamethasone Suppression Test in psychiatric patients with an without weight loss. Am J Psychiatry 142:246-248.

Krishnan KRR, France RD, Pelton S, McCann IJD, Manepalli AN, Davidson JRT (1985a): What does the Dexamethasone Suppression Test identify?. Biol Psychiatry 20:957-964.

Krishnan KRR, France RD, Snipes MT, Pelton S (1985b): Weight change and the Dexamethasone Suppression Test. Biol Psychiatry 20:1018-1022.

Kumar A, Alcser K, Grunhaus L, Greden JF (1986); Relationships of the Dexamethasone Suppression Test to clinical severity and degree of melancholia. Biol Psy. chiatry 21:436-444.

Lewis DA, Pfohl B, Schlechte J, Coryell W (1984): Influence of age on the cortisol response to dexamethasone. Psychiatry Res 13:213-220.

Meador-Woodruff JH, Haskett RF, Grunhaus L, Akil H, Watson SJ, Greden JF (1987): Postdexamethasone plasma cortisol and $\beta$-endorphin levels in depression: Relationship to severity of illness. Biol Psychiatry 22:1137 1150.

Miller KB, Nelson JC (1987): Does the Dexamethasone Suppression Test relate to subtypes, factors, symptoms. or severity?. Arch Gen Psychiatry 44:769-774.

Murphy BE (1967): Some studies of the protein-binding of steroids and their application to the routine micro- and ultra-micro measurement of various steroids in body fluids by competitive protein-binding radioassay. I Clin Endocrinol Metab 27:973-990.

Oxenkrug GF, Pomara N, McIntyre IM, Branconnier RJ, Stanley M, Gershon S (1983): Aging and cortisol resistance to suppression by dexamethasone: A positive correlation. Psychiatry Res 10:125-130.

Reus VI (1982): Pituitary-adrenal disinhibition as the independent variable in the assessment of behavioral symptoms. Biol Psychiatry 17:317-326.

Sangal R, Correa EI, DePaulo JR (1984): Depression and anxiety inventories and the Dexamethasone Suppression Test. Biol Psychiatry 19:1207-1213.

Spitzer RL, Endicott J (1975): Schedule for Affective Dis. orders and Schizophrenia. New York: Biometrics Research Division, New York State Psychiatric Institute.

Spitzer RL, Endicott J, Robins E (1977): Research Diagnostic Criteria ( $R D C$ ), New York: Biometrics Research Division, New York State Psychiatric Institute. 